\title{
El nuevo modelo competencial entre el Instituto Nacional Electoral y los organismos públicos locales electorales. Un federalismo en flujo
}

\author{
The Model of Coordination between INE \\ and its Local Counterparts. An Expresion \\ of Federalism in Flux
}

\section{Sergio Jesús González Muñoz*}

\section{Sumario:}

I. Introducción.

II. Federalismo electoral de riesgo.

III. Federalismo electoral retórico.

IV. Federalismo electoral de sentido común.

V. Federalismo electoral, cambio y tradición.

VI. Federalismo electoral de modernidad y en flujo.

VII. Federalismo electoral de retrotracción.

VIII. Conclusiones sobre el federalismo electoral de autocontención.

* Profesor de Organización de las elecciones y Derecho procesal electoral en la Facultad de Derecho de la UNAM. Ha sido funcionario del Instituto Federal Electoral, la Fiscalía Especializada para la Atención de Delitos Electorales y el Instituto Electoral del Distrito Federal. Colabora en medios impresos y electrónicos como analista jurídico y político acerca de temas electorales locales, nacionales e internacionales. 
Esta revista forma parte del acervo de la Biblioteca Jurídica Virtual del Instituto de Investigaciones Jurídicas de la UNAM

\section{Resumen:}

Desde su nacimiento como un órgano nacional cuasi único, el Instituto Nacional Electoral (INE) es producto de una profunda reforma constitucional y de las consecuentes reformas a las leyes secundarias en la materia. Dichos cambios no fueron producto de un análisis serio que sustentara la posibilidad de atender los problemas que su aprobación prometía resolver. Adicionalmente, el bajo contenido federalista del nuevo modelo competencial entre el INE y los organismos públicos locales electorales, tendiente al avasallamiento de los órganos locales, ha generado no sólo serias dificultades operacionales en su implementación, sino también, las más severas críticas provenientes de la academia, de los propios órganos electorales subnacionales, algunas reconvenciones jurisdiccionales notables, y en general, de un gran sector de los expertos mexicanos en estudios del federalismo.

\section{Abstract:}

Since its inception as an almost single national electoral regulatory body, the National Electoral Institute (INE) came to be as the product of constitutional and profound changes and consequent reforms to the secondary federal election laws. Such changes were not the product of a well thought, serious analysis that would support the possibility of solving the problems that its approval promised to accomplish. Furthermore, the somewhat non-federalist model of distribution of their respective mandates and scopes between INE and its subnational counterparts in the states, that apparently tends to overrun them, has generated as expected not only operational difficulties but also severe and harsh criticism from the academia, the local electoral bodies themselves, adverse election courts opinions and in general a large sector of the modern mexican experts in federalism studies.

Palabras clave: México, INE, IFE, autoridades electorales, federalismo, centralismo, elecciones federales, elecciones nacionales, elecciones locales, modelo competencial, competencias concurrentes, autonomía, reforma electoral, derecho electoral.

Keywords: Mexico, INE, IFE, electoral regulatory bodies, federalism, centralism, federal elections, national elections, local elections, autonomy, electoral reform, election law, model of election regulatory mandate, election regulatory scope. 


\section{Introducción}

El modelo actual de distribución de competencias entre el Instituto Nacional Electoral (INE) y las instituciones electorales locales, visible en el texto constitucional reformado en febrero de 2014 y en su reglamentación, es producto de una zona gris y de contornos borrosos en la argumentación jurídica de la iniciativa, de los dictámenes legislativos y de los debates parlamentarios.

Sin un sustento técnico analítico serio, el modelo se mantiene en flujo, entre avances y retrocesos y, paradójicamente, esa dialéctica tiende a estacionar su maduración óptima. Esta indefinición afecta no sólo el desempeño, eficacia y credibilidad de las autoridades electorales subnacionales, sino al INE mismo, pues no soluciona los dilemas que la reforma anunció que resolvería.

La encrucijada demanda una renovada reflexión sobre las coordenadas modernas del régimen federal, y sobre el arreglo institucional electoral que mejor sirve a los principios federalistas. Se trata, pues, de acercarse a un vértice del análisis electoral que se entrelaza con el estudio del federalismo, y de un análisis de éste que encarna en el ejercicio de la nueva rectoría electoral.

En otras palabras, la decisión constitucional que proyecta pulsiones centralistas hace que lo sean por su naturaleza, por su contenido y no por su denominación. Parece un silogismo extralógico, pero no lo es; considérese el caso del arraigo, que no por estar en la Constitución deja de ser una abominación procesal del más alto rango, actualmente considerada inconvencional.

Creo que el entorno obliga a revisar la nacionalización del INE, pues el nuevo modelo competencial no ha funcionado adecuadamente y empieza a revelar dificultades de continuidad con reconvenciones severas, antiguas y modernas, provenientes de los estados, de la jurisdicción electoral y de la academia.

Es menester entonces diagnosticar con seriedad y rigor los resultados de la nueva centralidad institucional y política, real o aspiracional, de la autoridad nacional y la creciente marginalidad a la que el esquema ha arrojado a los órganos electorales de los estados en lo que parecería una admonición de su final extinción.

Todo parece indicar que tanto la reforma constitucional de 2014, como la implementación fáctica que de ella viene realizando el INE, son un exceso, y en esa materia Jesús Reyes Heroles, magister de la apertura democrática mexicana y precursor de la modernización política electoral, 
tenía razón al señalar que no es posible neutralizar un exceso con un exceso contrario.

Este trabajo intenta analizar el origen y destino de esos excesos, en sus manifestaciones normativa y operativa, pero también proponer vías de salida o solución a una coyuntura delicada que debería llegar resuelta a la elección presidencial de 2018, bajo el otro principio reyesheroliano que reza: "lo que se soslaya estalla".

\section{Federalismo electoral de riesgo}

El federalismo electoral mexicano empezó a crujir desde 2007. En los debates de aquel año, en el marco dispuesto por la Ley para la Reforma del Estado, ${ }^{1}$ todas las fuerzas políticas, menos el PRI, se pronunciaron en sus documentos de propuesta por una sola autoridad administrativa nacional a cargo de todas las elecciones y la consecuente desaparición de los institutos y comisiones electorales del orden local.

A pesar de no contar con las mayorías necesarias en las cámaras del Congreso de la Unión para hacer avanzar sus intenciones, los partidos distintos al PRI lograron fisurar el muro tricolor. Producto de los pactos parlamentarios de la coyuntura, la reforma constitucional electoral de ese año incorporó la siguiente cláusula que expresó la simiente de una nueva forma de entender el pacto federal desde el punto de vista electoral y que anunciaba el porvenir: "El Instituto Federal Electoral asumirá mediante convenio con las autoridades competentes de las entidades federativas que así lo soliciten, la organización de los procesos electorales locales, en los términos que disponga la legislación aplicable". ${ }^{2}$

Con todo y su brevedad e imprecisión, la nueva norma, si atendemos la argumentación visible en el dictamen de las comisiones dictaminadoras del Senado, expresaba todavía cierta autocontención del legislador constitucional frente al pacto federal, pues señalaba que la reforma conjugaba armoniosamente la soberanía interior que la Constitución otorgaba a los estados, que se expresaba originariamente en su capacidad para organizar y desarrollar los procesos electorales relativos a los poderes públicos en su ámbito territorial con la posibilidad de aprovechar las capacidades

1 Ley para la Reforma del Estado (actualmente abrogada), Diario Oficial de la Federación, 13 de abril de 2007; disponible en http://www.diputados.gob.mx/LeyesBiblio/ abro/lre/LRE_abro.pdf (fecha de consulta: 11 de marzo de 2016).

2 Decreto que reforma diversas disposiciones de la Constitución de los Estados Unidos Mexicanos en materia electoral, Diario Oficial de la Federación, 13 de noviembre de 2007. 
materiales y humanas con las que contaba el Instituto Federal Electoral (IFE) en todo el país.

Del mismo modo, en un corto y mediano plazo (y esto sonaba muy atractivo), la modificación contribuiría a reducir costos y aumentar la eficacia y confiabilidad de los procesos electorales de orden local, con pleno respeto a la soberanía interior de las entidades federativas.

Si bien es cierto que aquella norma era tímida, no taxativa y, al parecer, con buenas intenciones, era también el aviso indubitable de una voluntad política de las élites legislativas y partidistas, de ponderar con toda seriedad una mera posposición del objetivo original de mucho mayor alcance.

En el prólogo de un texto fundamental de la época, que abordaremos más adelante, el entonces consejero presidente del órgano electoral jalisciense se dolía de que la iniciativa había sido omisa en señalar el estado de las capacidades materiales y humanas de los institutos electorales de los estados, "dado que sólo un diagnóstico confiable en el que se destacara la falta de capacidad de dichas instancias para acometer la organización de los comicios justificaría en alguna medida el notable cambio de orientación que se propuso". ${ }^{3}$

La atribución de la cláusula de marras, quizá por su pobre diseño, seguramente deliberado, no fue ejercida nunca, y jamás fue reglamentada; ello a pesar de que el gobernador de Tabasco, Arturo Núñez Jiménez, que había sido director general del IFE en los noventa y senador promotor de la reforma electoral de 2007, intentó infructuosamente en abril de 2013 acogerse al método para las elecciones locales del $2015 .^{4}$

A pesar del fracaso de 2007, el tema de reconcentrar en el IFE la articulación normativa y operativa de todas las elecciones mexicanas permaneció en la agenda de pendientes de los partidos por poco más de un lustro, y volvieron a la carga en 2013. En aquellas discusiones se apreciaban con toda claridad tres pulsiones políticas que inexplicablemente se comentaban, analizaban e impulsan como si fueran una sola, sin serlo:

- Se debía "amarrarle las manos a los gobernadores" ante la injerencia que, se dice, seguían teniendo en la conformación, y en el gobierno

3 Gómez Álvarez, David, “Prólogo”, en Astudillo, César y Córdova Vianello, Lorenzo, Los árbitros de las elecciones estatales. Una radiografía de su arquitectura institucional, México, Instituto Electoral y de Participación Ciudadana del Estado de Jalisco-UNAM, Instituto de Investigaciones Jurídicas, 2010.

4 "Piden que IFE realice comicios en Tabasco"; disponible en http://lasillarota. com/66334-piden-que-ife-realice-comicios-en-tabasco\#.VuQkwPl97IU (fecha de consulta: 12 de marzo de 2016). 
mismo y cotidiano de las autoridades electorales de sus entidades federativas.

- Para lograr eso, habría que transferir la preparación, desarrollo y calificación de las elecciones locales al IFE, por lo que, a su vez, deberían desaparecer las autoridades estales subnacionales.

- Excesivo gasto institucional electoral.

Es evidente que entre la primera y la segunda había un abismo argumental que sólo los interesados no querían ver, pues era evidente que de una cosa no se seguía la otra. Dicho de otra manera, "replegar" en estos temas a los ejecutivos locales era una cosa, pero otra muy distinta (y de ninguna manera conectada) dotar para ello al IFE de nuevas atribuciones y de personal que quizá terminaría por ser desnaturalizado; otra peor y aun menos relacionada, era desaparecer los institutos y comisiones electorales de los estados.

Si en realidad se quería prevenir, detener, castigar y reparar los "excesos" de los gobernadores en las elecciones locales, la solución era un análisis serio y serenado. Primero había que revisar en su conjunto las aristas de la discusión en todos los estados y en el Distrito Federal (DF), pues había actores que sólo veían la paja en el gobernador ajeno y no la viga en el propio. Segundo, lo que los quejosos llamaban "excesos", eran producto de normas aprobadas por ellos mismos a través de las expresiones parlamentarias de sus partidos políticos en los congresos locales, aunque hay que resaltar que en el caso del DF provienen de reglas aprobadas por el Congreso de la Unión en el Estatuto de Gobierno, que era por ello una ley federal.

Parafraseando a José Woldenberg, hacer lo que proponían los reformadores era equivalente a llegar a un hospital con un brazo fracturado, y que lo amputaran, en lugar de tomar una radiografía, enderezarlo y enyesarlo.

¿Entonces? Un buen inicio residía en una bien pensada reforma a los artículos 116 y 122 constitucionales que, aunque eran expresos y prolijos en los principios que deben regir la actuación de las autoridades administrativas electorales estatales y del DF, nada decían sobre los mecanismos para la designación de los titulares de los órganos superiores de dirección, y menos sobre los requisitos e impedimentos para su nombramiento o su remoción.

Esta omisión había ocasionado una variopinta camada de consejeros electorales en la que por igual destacaban doctores en ciencias políticas con obra publicada, que funcionarios o exfuncionarios públicos de enor- 
me experiencia y prestigio, que académicos o abogados de renombre, que honorables empresarios del ramo mueblero con especialidad en cocinas, con todas las variables que van de un extremo al otro, todos permitidos en las Constituciones y leyes locales.

Del mismo modo, teníamos consejeros cuyo término de gestión era de tres años con posibilidad de reelección no inmediata, como en Baja California, y otros que ejercían su encargo por siete años sin posibilidad de reelección, como en el DF. En casos peculiares, había consejeros que podían o no ser ratificados, e inclusive casos de consejeros con funciones acotadas exclusivamente al proceso electoral, y que el resto del tiempo se dedicaban a otra cosa, como en Nuevo León.

Así, como entonces era necesario combatir esta dispersión normativa y hacer del Cofipe una ley general para estandarizar a nivel nacional muchos procedimientos y plazos electorales que eran multitud e ininteligibles, también había que ponderar la inserción de reglas y principios generales que desde la Constitución restañaran la capacidad arbitral, prestigio y eficacia de los órganos estatales, con nuevos y mejores métodos de designación y hasta de remoción de sus consejeros electorales, así como requisitos e impedimentos más adecuados a la realidad política e institucional de las elecciones modernas, a poco más de dos décadas de la creación del IFE y de la primera generación de funcionarios especializados.

Por lo que hace al excesivo gasto electoral, se decía con ligereza que había un problema de gasto enorme en los órganos electorales estatales, pero no se entendía que lo que esas instituciones dejarían de gastar lo tendría que erogar el INE. Se omitía ponderar también que el personal de entonces, del IFE en los estados, no podría por sí mismo cumplir y hacer cumplir las atribuciones que en materia de elecciones estatales y ejercicios de participación ciudadana tenían los propios órganos locales, lo que implicaría la contratación (y en algunos casos, liquidación por duplicación de funciones) de personal de éstos.

Acaso, el estudio más serio e integral de la situación de las elecciones locales y sus autoridades administrativas no provino del análisis parlamentario, sino del académico, encarnado en la imprescindible obra enciclopédica de César Astudillo y Lorenzo Córdova, editada por el Instituto de Investigaciones Jurídicas de la UNAM y el Instituto Electoral de Jalisco en 2010: Los árbitros de las elecciones estatales. Una radiografía de su arquitectura institucional. ${ }^{5}$

5 Astudillo, César y Córdova Vianello, Lorenzo, op. cit. 
En su introducción, sin embargo, los autores presentaron este argumento, que nadie en San Lázaro y en Xicoténcatl escuchó en 2013:

toda propuesta en tal sentido (nacionalizar el IFE) no dejará de ser un alegato político carente de datos y justificaciones objetivas y racionales [...] Englobar a todos los institutos electorales en una indistinta categorización, sin hacerse cargo de sus diferencias institucionales, estructurales, funcionales y de desarrollo, parece ser una mala idea para fundamentar una propuesta de una envergadura y con un impacto tan profundo como el que se sugirió [...] constituye un despropósito que desplaza la historia individual de cada entidad federativa y hace caso omiso al empeño y el compromiso que muchos funcionarios electorales han demostrado en el transcurso de los años. ${ }^{6}$

\section{Federalismo electoral retórico}

Extrañamente, durante los debates de aquella época, los partidos inmersos en la discusión parlamentaria hacían promesas de respetar e impulsar el federalismo en sus documentos básicos entonces vigentes, alegatos que no se compadecían con lo que propugnaban en el terreno de los hechos en los plenos de las cámaras.

El PAN, en su programa de acción política de entonces, decía que "las competencias que inciden directamente en la vida del ciudadano deben ser atribuidas a los órdenes de gobierno más cercanos a la comunidad, y los gobiernos deben asumir responsablemente el ejercicio de las facultades que les son delegadas".

En sus principios de doctrina afirmaba: "En la realidad política mexicana [...] México debe ajustar su vida a los principios federales vigentes en la Constitución y superar el centralismo político en que vive, que mengua la autonomía de los estados, les impone autoridades y niega, con todo ello, los supuestos mismos de la Federación".

El PRD, en su programa de acción postulaba: "Se construirá un federalismo auténtico en el que se reivindique el carácter libre y soberano de los estados como entidades creadoras del Pacto Federal, para lo cual deberá observarse el principio constitucional por el cual quedan reservadas a los estados aquellas facultades no conferidas a los poderes federales".

En su Declaración de Principios, el PRI informaba: "Somos un partido político nacional de carácter federal [...] Su carácter federal radica en la fuerza integradora de estados y municipios. Queremos un Estado que

6 “Introducción", en ibidem, p. XXXV. 
garantice el pacto federal a través del fortalecimiento de las entidades federativas y el municipio libre".

En su programa de acción decía:

Nuestro federalismo se ha caracterizado por un alto grado de centralización, por lo que debemos replantear esa tendencia, perfeccionarlo y consolidarlo... Es impostergable el fortalecimiento del federalismo, y es necesario romper la inercia histórica en la que a pesar de tener un sistema federalista, ha imperado un modelo político excesivamente centralizado [...] El PRI [...] reconoce la capacidad de los estados, el DF y los municipios para tomar decisiones por sí mismos, sin que ello signifique el debilitamiento del pacto federal.

Finalmente, el dirigente del PRI dijo que, "es evidente que el INE (de la propuesta) es un mecanismo centralista [...] que efectivamente pueda, sin atropellar a las autoridades locales, ser capaz de articular esfuerzos y tener presente al personal que se ha capacitado durante decenas de años y que ha acreditado profesionalismo seriedad e imparcialidad".

\section{Federalismo electoral de sentido común}

Adicionalmente, la academia y los analistas políticos presentaron una suerte de frente común para frenar el atropello del que hablaba el presidente del PRI. La obra de Astudillo y Córdova, ya citada, no fue única pero sí la más socorrida a pesar de abordar los acuerdos de 2007, y de contar, en aquél momento político (2013), con seis años de antigüedad, por su riqueza en datos comparados entre los 32 órganos electorales subnacionales.

El análisis era serio:

Sin embargo, la discusión de esta posibilidad de concentración electoral no se dio sobre fundamentos empíricos. No existió un diagnóstico sobre el que se basara la posibilidad de concentrar la organización de las elecciones en una instancia central [...] los autores aceptan que la justificación que se da a la propuesta de reforma es persuasiva, señalan que se hizo sin considerar la opinión de las entidades federativas, y mucho menos, la de los institutos electorales. ${ }^{7}$

7 Gómez Âlvarez, David, “Prólogo”, en ibidem, p. XXI. 
Irma Méndez de Hoyos, en coautoría con Nicolás Loza, publicó, muy oportunamente, su texto "De la calidad de las elecciones a la calidad de las democracias en los estados mexicanos, 2001-2012" en el número 4 de la Revista Mexicana de Derecho Electoral de 2013.

Este par de obras eran las más recientes en ese momento, pero el análisis jurídico y político de los órganos electorales de los estados no era nuevo. En el prólogo de la ya mencionada obra de Astudillo y Córdova, Gómez Álvarez expuso el estado del arte de la investigación en la materia, al enlistar varios textos que, de haber sido consultados por los actores legislativos de aquel año, quizá hubieran contribuido a ilustrar la discusión: Crespo (1996); Arroyo y Morales (1999), Cetina (1999), Hernández (2003), Elizondo (2004), Peschard (2008) y Fernández (2009).

La opinión pública estaba prácticamente indefinida, según diversos ejercicios demoscópicos de aquellos días. La encuesta de Parametría, de marzo de 2013, reportó que sólo el 44\% de los entrevistados estaba de acuerdo en que desaparecieran los órganos electorales de los estados y que hubiera una sola autoridad nacional que se encargara de todas las elecciones mexicanas. ${ }^{8}$

A lo largo del mismo año, los analistas y comentaristas de los más diversos medios impresos y electrónicos también expresaron una franca oposición a la idea de construir una nueva autoridad electoral sobre las ruinas de los institutos y comisiones locales, y crearon un masa crítica de oposición a la medida que quizá logró detener, al menos temporalmente, el impulso político primario, lo que elevó el costo social y mediático de la decisión original. ${ }^{9}$

En el frente de los gobernadores, hay que destacar la abierta oposición que dos de ellos manifestaron. El jefe de Gobierno de la Ciudad de México (Mancera-PRD) y el gobernador del Estado de México (Ávila-PRI), en ese orden, expresaron en medios de comunicación su apoyo a la creación del ente nacional electoral, pero señalaron serias reservas sobre la desaparición de los órganos electorales locales. ${ }^{10}$

8 Parametría, marzo de 2013; disponible en http://www.parametria.com.mx/carta_ parametrica.php?cp=4585 (fecha de consulta: 12 de marzo de 2016).

9 Al analizar el proceso electoral 2015, Mauricio Rodríguez Alonso, ex consejero electoral del Instituto Electoral del Distrito Federal, escribió que la reforma de 2014 no funcionó, en su texto "Los retrocesos en materia electoral", Revista Big Data, octubre, p. 41.

10 Favela Herrera, Adriana, "Retos del Instituto Nacional Electoral en la designación de los consejeros electorales de los organismos públicos locales electorales", Revista Mexicana de Derecho Electoral, México, UNAM, Instituto de Investigaciones Jurídicas, núm. 6, julio-diciembre de 2014, pp. 291-317. 
Los mandatarios estatales restantes guardaron un disciplinado e indebido silencio, al tener la obligación de saber lo que estaba por suceder y de, quizá, defender la soberanía de sus entidades en materia electoral.

De los que serían los principales afectados, los órganos electorales de los estados, hay que decir muy poco. A pesar de haber sido advertidos en un momento procesal oportuno (mayo de 2013) de los contornos de la reforma constitucional y la creación del nuevo modelo competencial ${ }^{11}$ que los podría reducir a su mínima expresión o de plano suprimirlos, reaccionaron tarde (octubre) y mal. ${ }^{12}$ Se organizaron sin concierto ni orden en una asociación precaria de consejeros presidentes que, ya muy avanzados los debates parlamentarios, logró un par de audiencias con las comisiones dictaminadoras, pero que desperdiciando el micrófono y ocupados en luchas intestinas por alcanzar mayor protagonismo personal, no atinaron a presentar de manera clara, articulada y contundente sus argumentos.

\section{Federalismo electoral, cambio y tradición}

A pesar de todo esto, el PRI, que insistía en su resistencia de 2007, dejó pasar la reforma electoral de 2013, que creaba el IFE-Leviatán (ahora llamado INE) en un entorno complejo de varios frentes con apellidos energético, educativo, de transparencia y de telecomunicaciones como misiones particulares del Pacto por México, ${ }^{13}$ que no son sino rostros

11 Opinión de Sergio J. González M., La Crónica del Hoy, 22 de mayo de 2013; disponible en $h t t p: / / w w w . c r o n i c a . c o m . m x /$ notas/2013/755053.html. "La suerte y existencia misma de los órganos electorales de los Estados y del DF están atadas al parecer a la suerte y existencia del Pacto por México. La admonición parece inexorable en estos días, si tomamos como referencia el calendario reconfigurado en el adendum firmado hace unos días, mediante el que se anunció una discusión parlamentaria inminente en la materia [...] Inexplicablemente, el tema general de crear un órgano nacional de elecciones y suprimir los estatales discurre rápidamente por la comentocracia y en los comederos políticos como solución óptima e insustituible en la lucha contra dos demonios terribles: los apetitos políticos y de control de los gobernadores y el dispendio de recursos presupuestales en los comicios, sin contraargumentos sólidos todavía.

12 Véase "Se oponen a desaparición de institutos electorales locales y creación del INE"; disponible en http://plumaslibres.com.mx/2013/10/05/se-oponen-desaparicion-deinstitutos-electorales-locales-y-creacion-del-ine (fecha de consulta: 15 de marzo de 2016).

13 El compromiso 90 del Pacto por México decía: "Se impulsará una reforma electoral que atienda los siguientes temas: crear una autoridad electoral de carácter nacional y una legislación única, que se encargue tanto de las elecciones federales, como de las estatales 
constitucionalizados de un centralismo acendrado que resquebraja la dignidad histórica del pacto federal.

No resultó, empero, en el cumplimiento cabal de la exigencia de 2007, pues ni el modelo competencial electoral de 2014 se centralizó completamente en el INE, ni los órganos electorales administrativos de los estados y de la Ciudad de México desaparecieron del marco institucional. Estamos, pues, frente a un híbrido peculiar del que aún estamos conociendo sus alcances, y que genera tensiones y hace crujir la tradicional coordinación entre autoridades electorales del estado mexicano.

De inicio, hay que advertir que si bien el sistema federal de gobierno corresponde a determinado momento y lugar, en atención a configuraciones políticas, históricas, económicas y geográficas particulares, también es cierto que existen componentes fundamentales (cláusulas pétreas, si se quiere) que le dan consistencia en lo general. Dicho de otra manera, si bien el federalismo reside en la Constitución, no todo lo que reside en la Constitución con denominación federalista, necesariamente lo es.

Según los clásicos de la disciplina, la fortaleza del ente federal pasa obligadamente por la fortaleza de sus elementos. Es decir, erguido el método federal de gobierno, su resiliencia y su permanencia pasan por la de las entidades federativas que lo constituyeron en su origen.

Inclusive, nuestra norma fundamental caracteriza con esa naturaleza nuestra República federal, al expresar que es voluntad del pueblo mexicano constituirse en una República representativa, democrática, laica y federal, compuesta por estados libres y soberanos en todo lo concerniente a su régimen interior, y por la Ciudad de México, unidos en una federación establecida según los principios de esta ley fundamental, ${ }^{14}$ y que las facultades que no están expresamente concedidas por esta Constitución a los funcionarios federales, se entienden reservadas a los estados o a la Ciudad de México, en los ámbitos de sus respectivas competencias. ${ }^{15}$

La característica principal del modelo federal es la distribución del poder político con base en un consenso previo alcanzado por la voluntad de entidades políticas soberanas que, según la Conferencia Nacional de Gobernadores:

y municipales"; disponible en http://pactopormexico.org/PACTO-POR-MEXICO-25.pdf (fecha de consulta: 10 de marzo de 2016).

14 Constitución Política de los Estados Unidos Mexicanos, Diario Oficial de la Federación, 5 de febrero de 1917, última reforma 29 de enero de 2016, artículo 40; disponible en http://www.ordenjuridico.gob.mx/Constitucion/cn16.pdf (fecha de consulta: 10 de marzo de 2016).

15 Ibidem, artículo 124. 
acuerdan construir un orden superior de mando y autoridad para formar una nación única, a través de la que se gestione el desarrollo de lo que cada una de las entidades en forma aislada no pueda o le cueste lograr [...] El federalismo ya no puede significar en la práctica la sumisión de un nivel de gobierno a otro, sino al contrario, es a través de la actividad concurrente y coordinada entre los diferentes ámbitos de gobierno como el federalismo encuentra cauce y solidez. ${ }^{16}$

En el mismo texto, la propia Conago ${ }^{17}$ se quejaba de que cuando el poder federal se concentra en nombre de la gobernabilidad y el desarrollo económico, provoca la subordinación de los integrantes que hacen posible su existencia:

Aunque parezca contradictorio, [afirmaba la Conago en la introducción de Federalismo y descentralización,] este esquema centralista fue aplicado con relativo éxito por 70 años, no sin provocar serios desajustes y desigualdades, que son hoy materia de atención prioritaria [...] La lección que se deriva por haber relativizado los principios federalistas en la práctica gubernamental durante tanto tiempo puede dividirse en, por lo menos, cuatro tareas pendientes que se deben considerar para alcanzar un auténtico esquema federal. ${ }^{18}$

El federalismo mexicano proviene de una larga dinámica política que inició con la Independencia misma, y figura como principio axial de nuestras Constituciones, desde la de 1824, apenas reconvenido en pocas ocasiones, pero restaurándose siempre después de cada suspensión.

A lo largo de su evolución, nuestro modelo federal ha experimentado al menos tres fases: ${ }^{19}$ la originaria o germinal, la de consolidación y la del periodo posrevolucionario. La primera encontró sustento en la intención de crear una nación alrededor de un proyecto que reuniera a las partes

16 “Presentación”, Federalismo y descentralización, México, Conferencia Nacional de Gobernadores, Secretariado Técnico al Servicio de los Gobiernos Estatales, A. C., 2008, pp. 9-24.

17 Carbonell, José, “Transición a la democracia, gobernabilidad y federalismo. Cerrando el círculo", Federalismo y regionalismo. Memoria del VII Congreso Iberoamericano de Derecho Constitucional, México, UNAM, Instituto de investigaciones Jurídicas, 2002, p. 36.

18 “Presentación”, en op. cit., p. 21.

19 Serna de la Garza, José María, “Evolución y caracterización del sistema federal mexicano", Percepciones del federalismo mexicano. Encuesta nacional de federalismo, México, UNAM, agosto de 2015, pp. 29-54. 
para levantar un estado moderno que tuviera el dominio de su amplio territorio y soberanía política en el concierto internacional.

Durante las otras dos fases de su devenir, esta concepción original impregnó un matiz centralizador a la nación, justificado en la integridad nacional y en la viabilidad de una patria atenazada por las dolencias del crecimiento y de las amenazas del exterior, primero, y de la adolescencia y la madurez después, en un mundo crecientemente globalizado.

El centralismo retornó al escenario nacional a partir de la necesidad de la clase política de aquella época de trascender la lucha revolucionaria mediante un Poder Ejecutivo extraordinariamente fuerte, dominante y hegemónico, centro y vértice del sistema político entero.

Por su parte, la norma constitucional de 1917 seguía postulando el federalismo primigenio, pero la realidad política discurría por los ejes del presidencialismo hipertrófico, lo que, aunado a la implantación territorial del partido del presidente, sus mayorías imbatibles en el Congreso y su aquiescencia con la voluntad del Ejecutivo federal, así como la invisibilidad del Poder Judicial federal, terminó por avasallar y subordinar a los estados, creando un estado unitario de facto, revestido de formalidades federalistas.

\section{Federalismo electoral de modernidad y en flujo}

A partir de la transformación y apertura germinal del sistema político mexicano de finales de los ochenta, los instrumentos de control político de los que gozaba el presidente fueron mutando, en lo general, y perdiendo potencia, en lo particular, lo que dio vida plena a los otros poderes de la Unión y levantó de su letargo a las entidades federativas, pues señaladamente la Constitución recobró la fuerza normativa para la que fue concebida, y sus directrices torales, entre ellas el federalismo, renacieron con una gran dignidad jurídica a la vida pública, en medio de dinámicas de reacomodo de las fuerzas políticas.

Sin embargo, a pesar de que la norma fundamental establecía reserva formal en favor de los estados, en lo relativo a la distribución de competencias, dispuesta por el numeral 124, la realidad es que muy pocas materias se les han permitido en exclusiva a los estados, toda vez que el dilatado artículo 73, que enlista el catálogo de atribuciones del Congreso de la Unión, y que es el dispositivo más reformado de la carta magna, le 
ha ido acumulando atribuciones específicas al Congreso de la Unión en detrimento del pacto federal. ${ }^{20}$

No obstante, desde los setenta, la Constitución procuró avanzar en la ruta de la descentralización a través de las denominadas facultades concurrentes en diversas materias, como asentamientos humanos (1976), salubridad general (1983), equilibrio ecológico y protección al ambiente (1987), educación pública (1993), deporte (1999), turismo (2003), pesca y acuacultura (2003) y fomento de sociedades cooperativas (2004), "que no son otra cosa que la entrega al Congreso de la Unión de un poder sustantivo de dirección que le permite establecer un marco general de la política sectorial en la que goza de la facultad, pero dejando espacios más o menos amplios para que los estados puedan ejercer su potestad legislativa en la materia de que se trate". ${ }^{21}$

A estos avances, en la modernización del federalismo, se les puede contrastar con las disposiciones constitucionales modernas, mediante las que se establecen medidas de coordinación y sistemas articulados, como en el caso de la seguridad pública visible en las reformas de 1994 y 2008 que, siguiendo a Serna de la Garza, estableció un régimen de coordinación obligatoria, que se erigió en un freno a la descentralización.

Citando a Fernández Segado, Serna remata:

en nuestro caso, se trata de un federalismo "diferente", caracterizado por un inequívoco predominio del poder central, la naturaleza jerárquica del poder y de la autoridad, y la existencia de una relación de dependencia de unos poderes respecto de otros [...] la paradoja del caso mexicano está en que, siendo un estado formalmente federal, nuestro sistema tiene problemas típicos de un estado unitario. ${ }^{22}$

\section{Federalismo electoral de retrotracción}

En el entorno vigente, la paradoja ha migrado hacia las elecciones mexicanas por dos vías. En primer término la normativa, con las reformas constitucional y legal multicitadas de 2014, y, en segundo, la actuación institucional del INE en su relación de "coordinación" con los órganos

20 Ibidem, pp. 29-54.

21 Ibidem, p. 34.

22 Fernández Segado, Francisco, El federalismo en América Latina, México, UNAM, Cuadernos Constitucionales México-Centroamérica, núm. 41, 2003, p. 18. 
electorales subnacionales; en otras palabras, por el camino de las reglas y el de su aplicación.

Con el antecedente visto de la intención de los firmantes del Pacto por México por construir el INE encima de las ruinas de los institutos y comisiones locales, resulta claro que la reforma se quedó a medio camino, pero avanza la sensación ominosa de que en el futuro próximo los reformadores regresarán por lo que les faltó, y podrían alcanzar el objetivo inicial de 2007: cerrar los órganos electorales estatales y transformar al INE, ahora sí, en un órgano único a cargo de la organización de todos los comicios mexicanos.

En su interpretación y aplicación cotidiana de la nueva normativa constitucional y legal, el INE parece estar empeñado en avanzar en ese sentido, si revisamos con cuidado eventos y actuaciones particulares que apuntan en esa dirección.

Por ejemplo, es muy conocido el incidente nacional provocado por un mensaje de correo electrónico con un oficio anexo, de diciembre de 2015, mediante el cual autoridades centrales del INE le solicitaban a los organismos públicos locales electorales (OPLE) no solamente su calendario de vacaciones, que ya parece un exceso por tratarse de órganos autónomos, según las constituciones locales, sino los proyectos de presupuestos enviados a los respectivos congresos estatales.

En enero de 2016, se mandó a los organismos electorales locales un nuevo requerimiento en el que se solicitaba enviar al INE el documento por medio del cual fue aprobado el presupuesto de los OPLE, que diferenciaba las cantidades por gastos ordinarios, prerrogativas para los partidos políticos, y en los casos de las entidades con proceso electoral ordinario y extraordinario, lo correspondiente al gasto de ese proceso electoral, como si los institutos y comisiones locales fueran unidades de ejercicio del gasto del INE o como si fueran unidades administrativas ordinarias, componentes de la estructura jerárquica y línea de mando del ente nacional.

Mediante el acuerdo INE/CG865/2015, el Consejo General del INE emitió lineamientos de observancia obligatoria para la designación de servidores públicos titulares de las áreas ejecutivas de dirección de los OPLE, mediante una atribución que no le dieron ni la reforma constitucional ni las leyes generales derivadas, pero que existe expresamente en el catálogo de funciones exclusivas de los órganos de dirección de los órganos locales, visibles en las Constituciones y leyes estatales respectivas.

En esta área conviene recordar el caso de la Comisión Estatal Electoral de Nuevo León, cuyo órgano de dirección tuvo que ratificar en sus pues- 
tos a sus mandos superiores en acatamiento de estos lineamientos. Inclusive del secretario ejecutivo, cuyo nombramiento original había sido impugnado dos veces, pero que había sido confirmado en ambas por la Sala Superior del Tribunal Electoral del Poder Judicial de la Federación. ${ }^{23}$ Lo mismo sucedió en aquel estado en materia del diseño de su documentación electoral, pues el Consejo General de esa comisión tuvo que modificarlo para darle entrada a las casillas especiales, que no existen en la ley regiomontana. ${ }^{24}$

En relación con los límites a las aportaciones de carácter privado realizadas a los candidatos independientes durante el proceso electoral 20142015, el INE había fijado umbrales obligatorios muy bajos en su acuerdo INE/CG305/201, que la Comisión de Nuevo León tuvo que ampliar, acogiéndose a los mandatos del principio pro persona y maximización de derechos que dispone el artículo primero de la Constitución, citando inclusive instrumentos jurídicos internacionales de derechos humanos, así como jurisprudencia obligatoria de la Corte Interamericana de Derechos Humanos. ${ }^{25}$

En general, por los pasillos de los órganos electorales de las entidades federativas circula un sentimiento de desazón, pues el esquema de autoridad cuasi única nacional muestra otros aspectos de complejidad que hay que revisar.

Con frecuencia, los temas que más dificultades presentaron en el nuevo esquema de coordinación entre el INE y los OPLE fueron los siguientes: suscripción del convenio de coordinación, en cuyo proceso de diseño, revisión y firma, la voluntad central buscó siempre imponerse a las particularidades que los funcionarios electorales locales proponían y explicaban; comunicación cotidiana desarticulada, debido a que con frecuencia los funcionarios de las juntas locales y distritales del INE se dirigían de

23 Véase Acuerdo CEE/CG/144/2015, Consejo General de la Comisión Estatal Electoral de Nuevo León, en cumplimiento al Acuerdo INE/CG865/2015, Instituto Nacional Electoral.

24 Véase Acuerdo CEE/CG/117/2015, Consejo General de la Comisión Estatal Electoral, por el que se crean y modifican los diseños de los formatos de la documentación electoral a utilizarse en las elecciones locales de 2015, con motivo de la implementación de las casillas especiales.

25 La argumentación respectiva, del más alto nivel argumentativo, puede verse en el Acuerdo CEE/CG/121/2015, Consejo General de la Comisión Estatal Electoral, relativo a determinar los límites a las aportaciones de carácter privado realizadas a las candidatas y candidatos independientes durante el proceso electoral 2014-2015, derivado del Acuerdo INE/CG305/2015, Consejo General del INE. 
manera directa y hasta por escrito a los diversos órganos centrales y desconcentrados de los institutos y comisiones electorales locales, a veces, inclusive, los citaban a reuniones, sin considerar las líneas de mando al interior de los OPLE, con frecuencia establecidas en las leyes electorales locales; programa de resultados preliminares, las reglas del INE en varias ocasiones retrasaron los tiempos tradicionales en los estados para conocer los avances de los resultados electorales y se generaron presiones sociales, de los medios y de los candidatos estatales.

Otro tema fue el sistema de información de la jornada electoral, pues el modelo de operación del sistema no fue comunicado con la debida anticipación a los OPLE, y por lo tanto no todos tuvieron tiempo suficiente para hacer acopio de recursos humanos, materiales y financieros con la finalidad de tener lista la infraestructura necesaria; la entrega y recolección de paquetes electorales no fue debidamente ejecutada en los términos tradicionales de cada estado, de acuerdo con sus normas legales y reglamentarias; asimismo, se experimentó especial dificultad en la comunicación directa de los OPLE con los capacitadores asistentes electorales, lo que también ralentizó la atención oportuna de incidentes durante la jornada electoral.

En su mayoría, estos temas se podrían agrupar en uno solo: el modelo de casilla única, que representó novedosos retos en la ejecución de la nueva distribución de competencias entre el INE y los órganos electorales locales, en los aspectos siguientes: establecimiento del convenio general de coordinación y sus anexos técnicos; planeación y programación de actividades; seguimiento y control conjunto de las actividades convenidas; establecimiento de canales y flujos de comunicación conforme a la articulación institucional; emisión de normatividad y documentos técnicos; revisión e innovación de métodos electorales ante situaciones operativas y logísticas inéditas; así como en la operación funcional de las áreas centrales y de los órganos desconcentrados.

No se puede omitir el tema de la fiscalización de todas las campañas, partidos y candidatos de todo el país, también reconcentrada en el INE, cuyo ejemplo más preocupante es el de la elección extraordinaria de Colima y sobre lo que se podría escribir mucho.

Por su parte, el Tribunal Electoral del Poder Judicial de la Federación ha intervenido en los asuntos de excesos reglamentarios, normativos u operativos del INE, mediante los que, en detrimento de los órganos estatales de administración electoral y de las normas constitucionales y legales locales que los regulan, ha rebasado sus propias atribuciones e 
invadido las de los OPLE, y hasta de los congresos estatales, lesionando el pacto federal.

Téngase a la vista la resolución de la Sala Superior, recaída al expediente SUP-RAP-102/2016 y acumulados, en la que revocó el acuerdo del Consejo General del INE, identificado con la clave INE/CG63/2016, por el que, en ejercicio de la facultad de atracción, había emitido criterios generales a fin de garantizar el cumplimiento al principio de paridad de género en la postulación de candidaturas para todos los cargos de elección popular a nivel local.

En la parte conducente, el acuerdo original del INE decía, en el numeral 4 de su resolutivo segundo, que cuando fuera impar el número total de candidaturas postuladas por algún partido político, coalición o candidatura independiente - estos últimos únicamente por lo que hace a planillas para ayuntamientos- para un cargo de elección popular, el número mayoritario debería corresponder al género femenino.

Impugnado en apelación dicho acuerdo, por los partidos Morena, PRI, PT y PAN, la Sala Superior expresó que:

"asiste la razón a los partidos apelantes porque el Consejo General ejerció la facultad de atracción excediendo los parámetros establecidos para ello" en lugar de sentar criterios interpretativos "tendentes a armonizar la coexistencia de las reglas establecidas en las legislaciones electorales locales con los criterios jurisprudenciales obligatorios para garantizar la paridad de género en la postulación de candidatos"

\section{[...]}

Tal como lo sostienen los partidos apelantes, con esta forma de proceder, el Consejo General vulnera la libertad de configuración legislativa de las entidades federativas en materia de paridad de género, porque no se ocupa de realizar un ejercicio interpretativo a efecto de lograr coexistencia de las normas [...] Más bien, lo que hace el Consejo General equivaldría a ejercer el control indirecto de las reglas locales, porque toma en cuenta las reglas previstas en las legislaciones generales electorales. ${ }^{26}$

En la normativa interna de los partidos, y en lo sostenido por la Suprema Corte y la propia Sala Superior en diversas ejecutorias y jurisprudencias, "el Consejo General define verdaderas nuevas reglas generales y

26 Apartado "Estudio de fondo" de la sentencia, epígrafe "V Aplicación al caso concreto", sub apartado “3 Exceso en el ejercicio de la facultad de atracción”, pp. 29 y ss. 
vinculantes $[\ldots]$ sin valorar de forma particularizada y a la luz del contexto de cada entidad federativa la pertinencia de ello".

A mayor abundamiento, la Sala Superior reconviene al Consejo General, denunciando que es improcedente y, desde un punto de vista constitucional, también un ultraje al pacto federal lo dispuesto en el numeral 13 del resolutivo segundo del acuerdo de marras, toda vez que los llamados criterios interpretativos establecidos prevalecerían sobre las disposiciones constitucionales y legales que se opusieran a lo dispuesto en dicho acuerdo. $^{27}$

\section{Conclusiones sobre federalismo electoral de autocontención}

1. La reforma constitucional de febrero de 2014 y las legales de mayo de ese mismo año, crearon un nuevo modelo competencial electoral que empieza a mostrar nudos que dificultan su maduración institucional y amenazan su continuidad en los términos de su concepción, por haberse realizado sin un diagnóstico serio y sin un estudio profundo de las capacidades de las entidades electorales subnacionales.

2. El modelo competencial fue aprobado de manera legítima en términos de su ajuste a derecho, en tanto procedimiento de reforma normado en la propia Constitución, pero se realizó a contrapelo de una gran franja opositora al cambio, integrada por amplios sectores de la academia, de los analistas especializados de los medios escritos y electrónicos, y de, cuando menos, los ejecutivos locales de las dos entidades federativas más pobladas del país: el DF y el Estado de México.

3. En el diseño y aprobación del modelo, el legislador constitucional no escuchó a los órganos electorales de las entidades federativas, si acaso se les atendió poco y mal durante la fase final de su discusión. Por su parte, estos últimos reaccionaron tarde, lenta y desarticuladamente, facilitando la reforma que por poco los suprime, pero que los tiene en la ruta de desaparición.

4. En la confección de la reforma tampoco se escuchó al entonces IFE, a pesar de que se le adicionarían decenas de nuevas atribuciones, lo que

27 El Resolutivo Segundo del Acuerdo INE/CG63/2016 en su numeral 13 dice: "En el caso de que las Constituciones o legislaciones locales establezcan disposiciones que resulten en una mejor garantía para el cumplimiento del principio de paridad de género, dichas disposiciones prevalecerán sobre el presente Acuerdo. Por el contrario, este Acuerdo prevalecerá sobre las disposiciones (constitucionales y legales locales) que se opongan a lo establecido en los presentes criterios". 
lo convirtió en una pesada y gigantesca nave difícil de maniobrar en las procelosas aguas de la contienda electoral y el financiamiento de la política.

5. Frente a la sobrecarga, el ahora INE podría resentirse, no sólo en su eficacia y credibilidad, sino también en su legitimidad política arbitral y en su tradicional reconocimiento social.

6. Este tema no le es ajeno ni indiferente a la sociedad mexicana. Durante 2013, diversas casas encuestadoras publicaron los resultados de sus ejercicios demoscópicos. Uno de ellos, en particular, el de la empresa Parametría, preguntó a los 12800 entrevistados (cara a cara en vivienda entre el 10 y el 23 de marzo) si estaban de acuerdo en que desaparecieran los órganos electorales de los estados, y que hubiera una sola autoridad nacional que se encargara de todas las elecciones mexicanas. Sólo el 6\% no supieron o no quisieron contestar el cuestionario, mientras que apenas el 44\% de los encuestados respondió afirmativamente.

7. Desde su diseño normativo, el modelo trastorna la ingeniería federalista dispuesta en la Constitución general de la República; desde su operación fáctica atropella la soberanía política y legislativa de las entidades federativas en general.

8. En especial, el modelo infringe e invade, también indebidamente, las atribuciones de los congresos locales y de los órganos subnacionales electorales, de los que han emergido innovaciones jurídicas y operativas desde hace lustros, y que apenas ahora empiezan a recogerse en las normas y procedimientos electorales federales.

9. En su afán homogeneizador, el modelo soslaya particularidades locales que sin un ajuste adecuado pueden tender a dañar la capacidad arbitral y el prestigio pericial que los órganos comiciales estatales necesitan retener en beneficio de la estabilidad política y la gobernanza electoral de sus jurisdicciones regionales.

10. Por la vía de consecuencia, el sistema federal mexicano entero se resiente por la desnaturalización correspondiente que se da en los hechos, y aunque el modelo se considere constitucional, en realidad es sólo constitucionalizado.

11. Adicionalmente, las grandes decisiones de la nueva autoridad nacional, cuando menos en lo relativo a los mecanismos de coordinación y comunicación con los órganos electorales de las entidades federativas, parecen transitar a lo largo y ancho de una convicción institucional y colegiada de darles trato de entes subordinados o de menores de edad.

12. Se percibe una creciente inconformidad de las autoridades electorales subnacionales con los instrumentos y herramientas de la aplicación 
y ejecución cotidiana del modelo, así como con la interpretación y argumentación jurídica que les da soporte, y ello parece confrontarnos con los capítulos iniciales de una tendencia que podría resultar, en su punto más alto, en impactos y desenlaces políticos y administrativos indeseables.

13. Tan laxo es el modelo en sus contornos, que la jurisdicción electoral empieza a descifrarlos y/o determinarlos a golpe de resoluciones por ahora, y seguramente de jurisprudencia a mediano plazo, mediante reconvenciones severas a la autoridad nacional por sus incursiones en terrenos competenciales que le están constitucionalmente vedados.

14. El modelo debe ajustarse pronto y bien, orientado por un análisis serio y objetivo, quizá con la comisión de un tercero para garantizar mayor objetividad y pericia técnica, como una entidad u organización académica o gremial, o conjunto de ellas, con credenciales científicas ciertas, suficientes y adecuadas cuya experiencia y familiaridad con el componente federal de nuestro régimen político pueda contribuir a esclarecer la cuestión.

15. En realidad, la tarea podría ser desplegada con soltura y dominio por el Instituto de Investigaciones Jurídicas, el Secretariado Técnico de la Conferencia Nacional de Gobernadores, la Conferencia Permanente de Congresos Locales, el Instituto Nacional de Administración Pública, la Conferencia de Diputados de la República o la Asociación Mexicana de Institutos y Organismos de Estudios e Investigaciones Legislativas, quizá en convenio con el Instituto Nacional para el Federalismo y Desarrollo Municipal de la Secretaría de Gobernación, con el Instituto de Estudios del Federalismo del Estado de Jalisco o con uno o varios de los centros de estudios de las cámaras del Congreso de la Unión.

16. A la vista de los resultados del estudio o diagnóstico referido, habría que emprender la tarea de acotar el modelo competencial a su dimensión objetiva, racional, determinada con las herramientas más modernas y acreditadas del derecho y de la ciencia política, catalizando un proceso legislativo de ajuste cuando menos al apartado correspondiente del artículo 41 constitucional, el de la distribución competencial original, y la normativa ordinaria de orden legal, que desarrolla y controla las variables particulares de dicha distribución.

17. En esta empresa resulta imprescindible escuchar a los gobernadores, a los congresos locales y, por necesidad, a los institutos y comisiones locales, junto con una lectura desapasionada de las resoluciones judiciales aplicables al caso, y una revisión de la doctrina más actualizada de la especialidad electoral, pero también la del federalismo moderno. 
Esta revista forma parte del acervo de la Biblioteca Jurídica Virtual del Instituto de Investigaciones Jurídicas de la UNAM

18. Muy especialmente habría que considerar una conferencia nacional, o varias regionales, en las que se reunieran los OPLE e INE a evaluar con método, apertura y agenda las vicisitudes de la aplicación del nuevo modelo competencial, a la luz de un proceso de mejora continua, comprometido con las mejores prácticas y principios federalistas, que refuerce la coordinación y la comunicación entre pares.

19. En este nuevo modelo competencial en flujo, a veces desbordado, a veces en retrotracción, a veces en proceso de avance, la norma ajustada podría generar nuevas conductas institucionales, pero aún sin reforma, nuevas conductas y convicciones democráticas podrían cambiar paradigmas de desarrollo e implementación institucional, que a su vez, podrían fortalecer la viabilidad política, y quizá hasta crear la necesidad de una reforma como la que las elecciones y el federalismo mexicanos merecen en esta materia. 